\title{
Correlation between nuclear response and defects in CZT
}

\author{
H. Hermon ${ }^{2}$, M. Schieber ${ }^{\text {aa }}$, R.B. James ${ }^{b}$, E. Lee ${ }^{b}$, E. Cross ${ }^{b}$, \\ M. Goorsky ${ }^{c}$, T. Lam ${ }^{c}$, T.E. Schlesinger ${ }^{d}$, M. Greaves ${ }^{d}$ \\ ${ }^{2}$ The Hebrew University of Jerusalem, Jerusalem 91904, Israel \\ ${ }^{\mathrm{b}}$ Sandia National Laboratories, Livermore, CA 94550 \\ ' University of California - Los Angeles, Los Angeles, CA 90024 \\ ${ }^{\mathrm{d}}$ Carnegie Mellon University, Dept. of Elec. Eng., Pittsburgh, PA15213

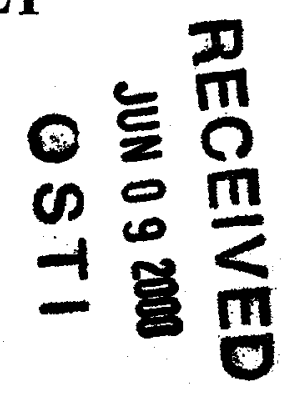

\begin{abstract}
Vertical high pressure Bridgman (VHPB) was considered until now to be the most successful crystal growth method to produce $\mathrm{Cd}_{1-x} \mathrm{Zn}_{\mathrm{x}} \mathrm{Te}(\mathrm{CZT}),(0.04<\mathrm{x}<0.24)$, for $\mathrm{X}$ - and gamma-ray detector crystals. Recently Horizontal Bridgman (HB) $\mathrm{Cd}_{1-x} \mathrm{Zn}_{\mathrm{x}} \mathrm{Te}$ crystals produced by IMARAD Co. have also been successfully fabricated into nuclear spectroscopic radiation detectors. In view of our database of many years' study of the electrical properties of VHPB CZT grown and obtained from various sources, we also studied the HB CZT crystals in order to compare the defects present in both different kinds of crystals grown by different methods. The VHB-grown samples were examined using thermoelectric emission spectroscopy (TEES), X- and gamma ray spectroscopy and laser induced transient charge technique (TCT). The surface and the bulk crystalline homogeneity were mapped using triaxial double crystal x-ray diffraction (TADXRD) and infrared transmission spectroscopy (IR). We have found a correlation between crystallinity, $\mathbb{R}$ transmission microstructure and trapping times. Spectrometer grade VHPB CZT crystals exhibit trapping times of $20 \mu \mathrm{s}$ for electrons and $7 \mu \mathrm{s}$ for holes, however, regions, which were opaque to $\mathbb{R}$ transmission, had trapping times shorter by one order of magnitude. The trapping times of HB CZT for electrons, were 10-15 $\mu$ s. A similar trend has been observed on VHPB CZT crystals with poor crystallinity. The HB CZT crystals that we measured in this study had a crystallinity that was inferior to that of the best spectroscopic grade VHPB crystals.
\end{abstract}

Keywords: Cadmium Zinc Telluride (CZT), X-ray diffraction (XRD), Horizontal Bridgman (HB), vertical high pressure Bridgman (VHPB), IR transmission, and transient charge technique (TCT).

\section{INTRODUCTION}

$\mathrm{Cd}_{1-\mathrm{x}} \mathrm{Zn}_{\mathrm{x}} \mathrm{Te}$ crystals, with $0.05<\mathrm{x}<0.4$, are leading materials for room-temperature operating radiation detector applications [1-5]. Due to the addition of $\mathrm{Zn}, \mathrm{CZT}$ has a larger energy gap than CdTe and therefore has some distinct advantages over CdTe by having a higher value of bulk resistivity, lower dark current and reduced electronic noise. Crystal growth of CZT has been performed by various methods, however until recently, it is performed mainly by a vertical high-pressure Bridgman (VHPB) process for producing of gamma-ray detectors. Indeed, recently, ambient pressure horizontal Bridgman (HB) crystals became commercially available, and spectrometric grade detector were fabricated and tested by Sandia National Laboratories. A large number of papers were published by the Sandia group to characterize the various VHPB grown CZT crystals produced commercially in the US and in parallel, CZT crystals grown in Russia [6-11] and in the Ukraine were also evaluated $[6,10]$.

Better understanding of the growth parameters is a must in order to improve the material quality. Therefore, the opportunities to study in parallel the VHPB and the HB crystals offer an excellent occasion to compare both types of crystal growth process. It is known that defects are much less common in spectrometer grade CZT detectors. If the spectrometric grade is of lower quality it is often be due to microstructural defects $[8,11-13]$. These defects are typically generated during the crystal growth process, although the fabrication steps can also introduce defects.

The present paper will show here our first results obtained on HB CZT using X-ray diffraction, XRD, which show the $\mathrm{Zn}$ content. Low temperature photoluminescence, PL, and Triaxial XRD, TAD-XRD, and XRD topography will also be shown. Alpha particle spectroscopy is one of the most common methods used to evaluate the electrical properties of wide

'Correspondence: Email: schieber@vms.huji.ac.il Phone: +972-2-6584364; FAX +972-2-5663878 
band gap semiconductors, however, it appears that the highly imperfect regions of the detectors do not respond to alpha radiation and hole transport properties are difficult to quantify. In order to evaluate the electrical properties of those regions, a much more intense source of energy is required to produce detectable electron hole pairs. One possible source is a pulsed laser, which produces many orders of magnitude creating more charges in each pulse. Indeed, we applied the transient charge technique, (TCT) method to study the trapping time of HB crystals, and compare them with the VHPB crystals. Finally, some preliminary data on thermoelectric voltage spectroscopy (TEVS) and thermal stimulated current, (TSC) results, will also be shown.

$\therefore$...

$\beta_{\infty}$

\section{RESULTS AND DISCUSSION}

\section{The Zn content}

The $\mathrm{Zn}$ content, $\mathrm{x}$ in $\mathrm{HB} \mathrm{Cd}_{1-\mathrm{x}} \mathrm{Z} \mathrm{n}_{\mathrm{x}} \mathrm{Te}$ crystals was determined by XRD using Vegard's law [14]. Two samples were measured: the thin sample was $3 \mathrm{~mm}$ thick and looked quite homogeneous. The thicker sample could only be measured from the front side, so only one measurement was taken. The results are shown in Table 1.

Table 1. Zinc content in HB-CZT

\begin{tabular}{|l|l|l|}
\hline & Small sample & Large sample \\
\hline Front & $9.416 \%$ & $8.999 \%$ \\
\hline Back & $9.872 \%$ & \\
\hline
\end{tabular}

The Zn content was determined by similar XRD andor PL measurements for CZT having a minimal composition of $10 \%$ $\mathrm{Zn}$ compared to VHPB crystals from 6-12\% depending on the distance from the seed to the top of the grown crystal boule. The HB crystals measured so far produced to small data base to make a comparison regarding the structural homogeneity of the grown crystals.

\subsection{Elemental chemical analysis}

A CZT detector obtained from Imarad has been analyzed for its elemental impurities. The elemental analysis results were compared with CZT samples obtained from Russia and from U.S. (see Fig 1). The Figure shows the elemental impurity analysis measured on the Imarad HB CZT, using a glow discharge mass spectroscopy (GDMS) method. A comparison of the elemental analysis results with the results measured on HPVB CZT grown in Russia and HPVB CZT grown in the U.S. is given in Table 2. The most abundant impurities found in the HB CZT are In and Fe with 6 and 1 ppmw respectively; In was probably introduced to the sample during the fabrication process. Other noticeable impurities are $\mathrm{Li}, \mathrm{Si}, \mathrm{Se}$ and $\mathrm{Ag}$, The concentrations of other impurities were in the range of 10-100 ppbw. About the same impurity level has also been found also on the U.S. grown HPVB CZT using the laser ablation inductively coupled plasma (LA-ICP) method. The Russian grown CZT, on the other hand, has a higher impurity level by one order of magnitude with a high level of Se ( 2ppm).

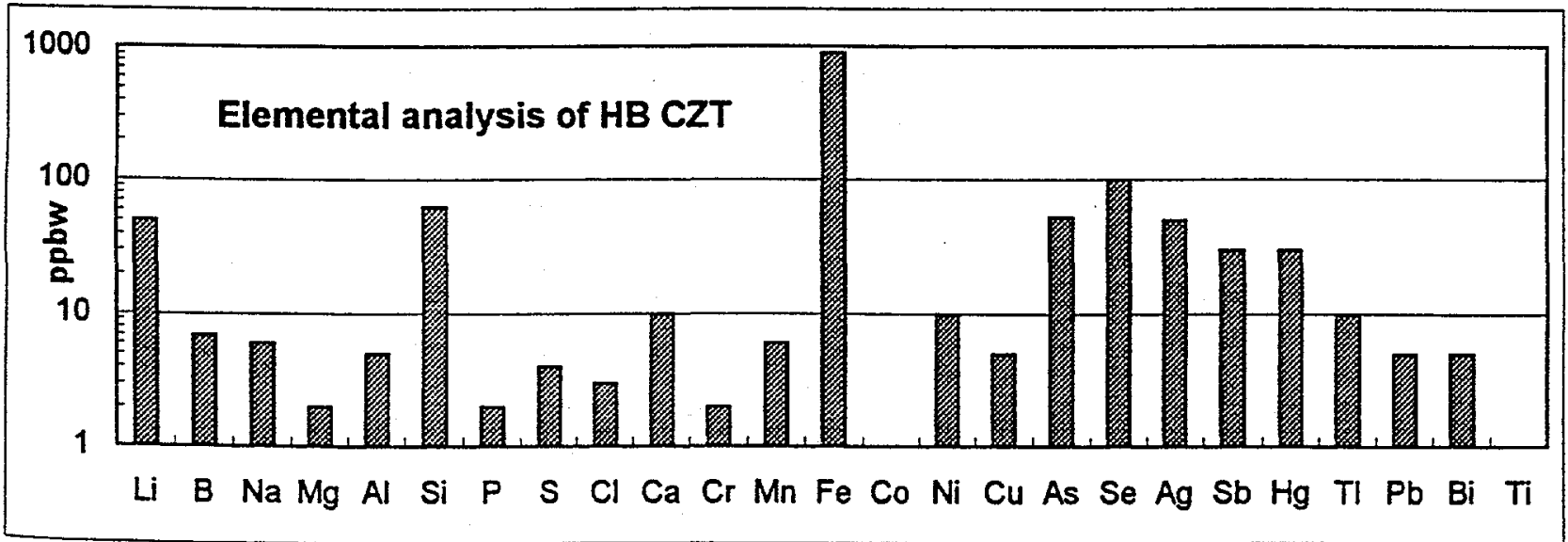

Fig. 1. Elemental analysis of $\mathrm{HB} \mathrm{CZT}$ 


\section{DISCLAIMER}

This report was prepared as an account of work sponsored by an agency of the United States Government. Neither the United States Government nor any agency thereof, nor any of their employees, make any warranty, express or implied, or assumes any legal liability or responsibility for the accuracy, completeness, or usefulness of any information, apparatus, product, or process disclosed, or represents that its use would not infringe privately owned rights. Reference herein to any specific commercial product, process, or service by trade name, trademark, manufacturer, or otherwise does not necessarily constitute or imply its endorsement, recommendation, or favoring by the United States Government or any agency thereof. The views and opinions of authors expressed herein do not necessarily state or reflect those of the United States Government or any agency thereof. 


\section{DISCLAIMER}

Portions of this document may be illegible in electronic image products. Images are produced from the best available original document. 
Table 2. Elemental analysis (ppbw) of Imarad HB CZT (Imarad), HPVB-CZT (US grown) and HPVB-CZT (Russian grown).

\begin{tabular}{|c|c|c|c|c|c|c|c|}
\hline $\begin{array}{l}\text { Element } \\
\qquad \mathrm{Ag}\end{array}$ & $\begin{array}{c}H B \text { (ppb) } \\
50\end{array}$ & $\begin{array}{c}\text { US-HPVB } \\
\text { (ppb) } \\
70\end{array}$ & $\begin{array}{c}\text { Russian-HPVB } \\
\text { (ppb) } \\
\text { nd }\end{array}$ & $\begin{array}{c}\text { Element } \\
\qquad \mathbf{L i}\end{array}$ & $\begin{array}{c}H B \text { (ppb) } \\
50\end{array}$ & $\begin{array}{c}\text { US-HPVB } \\
\text { (ppb) } \\
1\end{array}$ & $\begin{array}{c}\text { Russian-HPVB } \\
\text { (ppb) } \\
1\end{array}$ \\
\hline Al & 5 & 20 & nd & $\mathrm{Mg}$ & 2 & 10 & nd \\
\hline As & 53 & 20 & nd & $M n$ & 6 & 20 & 42 \\
\hline $\mathbf{B}$ & 7 & 1 & 510 & $\mathbf{N a}$ & 6 & 7 & nd \\
\hline Bi & 5 & 100 & 35 & $\mathbf{N i}$ & 10 & 40 & 253 \\
\hline $\mathbf{C a}$ & 10 & 10 & nd & $\mathbf{P}$ & 2 & 20 & nd \\
\hline Cl & 3 & 10 & nd & $\mathbf{P b}$ & 5 & 20 & 344 \\
\hline Co & 1 & 20 & 10 & $\mathbf{s}$ & 4 & nd & nd \\
\hline $\mathrm{Cr}$ & 2 & 20 & 79 & Sb & 30 & 80 & nd \\
\hline $\mathrm{Cu}$ & 5 & 50 & nd & $\mathrm{Se}$ & 100 & 300 & 2174 \\
\hline $\mathrm{Fe}$ & 910 & 70 & 910 & $\mathbf{S i}$ & 63 & 80 & nd \\
\hline In & 6300 & nd & 400 & $\mathrm{Ba}$ & nd & 358 & 905 \\
\hline $\mathbf{H g}$ & 30 & nd & nd & $T$ & 10 & 100 & 52 \\
\hline
\end{tabular}

\subsection{Life time measurements}

We have evaluated CZT samples obtained from various vendors by measuring their electrical transport properties, i.e. the mobility $\mu$, and trapping lifetimes $\tau$, for electrons and holes. The pulsed laser transient charge technique (TCT) method was used [13]. The system is equipped with a vacuum test chamber, transparent window on top, $\mathrm{LN}_{2}$ cold temperature stage and a LSI UV pulsed laser model VSL-337. The pulse width is 3 nsec with energy of $120 \mathrm{~mJ}$ per pulse, which is enough to produce $1.5 \times 10^{14}$ electron hole pairs for each pulse. The output from the detector is sufficiently high so that the need for additional amplification stages is eliminated. This enables reading of the transients at low bias conditions, which is required for measuring the trapping times. Measuring the detrapping times is also possible at low temperature conditions [13].

Table 3. Typical lifetimes measured on HPVB and HBCZT crystals from various sources.

\begin{tabular}{|c|c|c|c|}
\hline Sample & electron-lifetimes $\tau_{e}$ & hole-lifetimes $\tau_{k}$ & Resistivity (ohm) \\
\hline 1"xl" HB CZT & $10-15$ & $2-3$ & $\sim 10^{9}$ \\
\hline Lifetimes $\tau$, Range for detector grade CZT & $3-20 \mu S$ & $1-7 \mu s$ & $10^{11}$ \\
\hline $\begin{array}{l}\text { Lifetimes } \tau \text {, on US grown CZT with higher } \\
\text { impurity level (last-to-freeze zone) }\end{array}$ & $1-6 \mu s$ & $0.5-3 \mu \mathrm{s}$ & $10^{10}-10^{11}$ \\
\hline Near grain boundary on US grown CZT & $6-7 \mu \mathrm{s}$ & $3 \mu \mathrm{s}$ & $10^{10}-10^{11}$ \\
\hline $5 \times 5 \times 2 \mathrm{~mm}$ US grown CZT detector & $15-20 \mu s$ & $3 \mu \mathrm{s}$ & $10^{11}$ \\
\hline Russian "good" & $0.5-2 \mu s$ & $-0.1 \mu \mathrm{S}$ & $10^{9}-10^{10}$ \\
\hline Russian "bad" " & $<0.2 \mu s$ & not available & $10^{8}$ \\
\hline
\end{tabular}

Table 3 compares the lifetimes $\tau_{\mathrm{c}}$ and $\tau_{\mathrm{h}}$ of various vertical (high pressure) and horizontal low pressure horizontal Bridgman CZT. From Fig. 2 it can be seen that detrapping due to shallow traps is present.

Figure 2 shows a transient from HB CZT grown By Imarad. The waveform was recorded at a low electric field of $10 \mathrm{~V} / \mathrm{mm}$, the transit time $\operatorname{Tr}$ is $\sim 3 \mu \mathrm{s}$, which is shorter than the detrapping time $\tau_{\mathrm{D}}$ of $\sim 160 \mu \mathrm{s}$ (i.e. Tr<t, therefore, one can set that detrapping is the major component in the resulting waveform). This type of waveform is typical for semiconductors with high level of shallow traps [13]. 


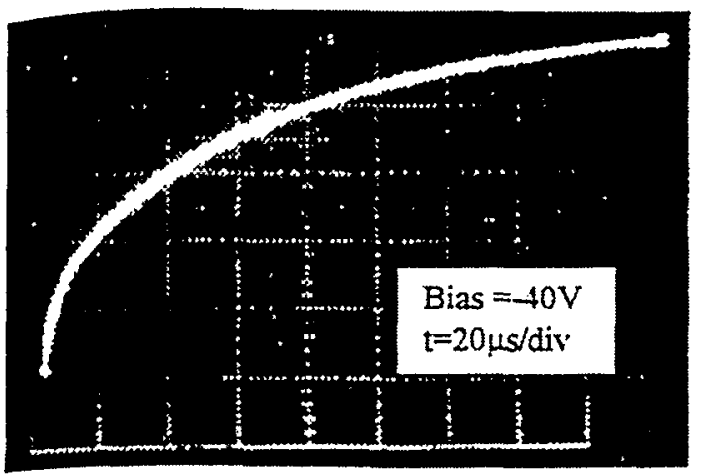

Fig. 2. Electron transient waveform from $\mathrm{HB} \mathrm{CZT}$ exhibit high level of detrapping originated from shallow traps

\subsection{Photoluminescence measurements}

Fig. 3 displays photoluminescence spectra from three points on a sample of HB (IMARAD)-grown CZT at a temperature of 4.2 $\mathrm{K}$. The temperature was maintained by immersing the sample in liquid helium, using a Cryo Industries model 800 low temperature dewar. A $25 \mathrm{~mW}$ He-Ne laser was used as an excitation source, and focused on the sample. The resulting luminescence was collected using a series of lenses, and focused into a SPEX1404 Double Pass Spectrometer, with an entrance slit width of $1 \mathrm{~mm}$ corresponding to a spectral resolution of $3 \AA$. A Hamamatsu GaAs photomultiplier tube and a Stanford Research Systems SR440 Photon Counter were used to detect the luminescence. The photomultiplier tube was biased to -1800 volts, and the resulting signal amplified with a gain of 25 by two successive stages of a Stanford Research Systems $1404 \mathrm{DC}-300 \mathrm{MHz}$ amplifier before analysis by the photon counter at a discriminator voltage of $-20 \mathrm{mV}$. The spectrum was taken from 7000 to $9000 \AA$ in one $\AA$ increments, with a scan time of $0.5 \mathrm{sec} / \AA$.

iemperiture $=4.2 \mathrm{~K}$

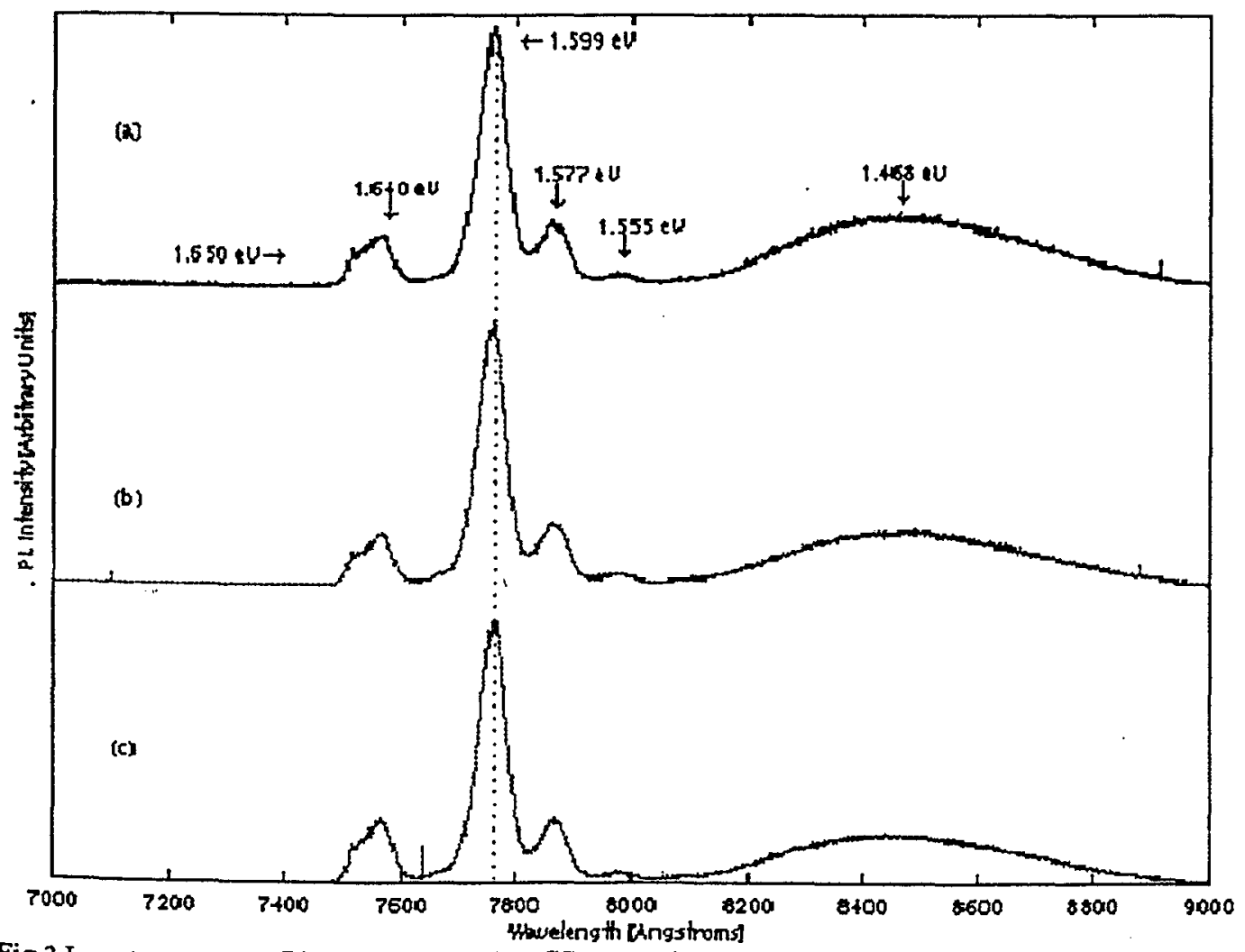

Fig.3 Low temperature Pl spectrum of a HB-CZT sample 
The resulting spectrum is dominated by donor-acceptor luminescence in the 7700 to $7800 \AA$ or 1.611 and $1.590 \mathrm{eV}$ range. Additionally, the $1.577 \mathrm{eV}$ and $1.555 \mathrm{eV}$ peaks correspond to donor-acceptor first and second phonon emissions. The large broad peak in the 8900 to $9000 \AA$ range is representative of A-center, or acceptor-bound emissions. Finally, the least resolved, higher energy peak in the 7480 to $7600 \AA$ ranges is the excitonic band of emissions.

Across the three sampled regions, the spectra show little variation in the peak position characteristic of good uniformity in the material composition. The spectral line widths, however; are not as well resolved as the best HPVB CZT, suggested lower uniformity.

\subsection{X-ray diffraction experimental data}

A Bede $D^{3}$ diffractometer was used for triple axis $x$-ray diffraction measurements (TAD). The triple-axes refer to i) a beam conditioning axis, ii) the sample stage, and iii) analyzer crystal axis. Si (111) with (+,-,-) configuration was used for the beam collimator/monochromator and $\mathrm{Si}(220)(+,-,+)$ was used for the diffracted beam analyzer crystal. Double axis $\mathrm{x}$-ray topography (DAXRT) measurements were performed using a modified Bede 150 diffractometer with a Si single crystal to match the substrate curvature [15]. The crystal is miscut by $7.3^{\circ}$ from the (001) towards a [110], providing a $1.5^{\circ}$ angle between the incident $\mathrm{Cu} \mathrm{K} \alpha$ radiation and the surface for the (224) reflection. Two samples were measured, one larger whose $\mathrm{Zn}$ content was measured using the Vegard's law [14] and one smaller sample, where both the $\mathrm{Zn}$ content and the crystallinity were measured as determined by TADXRD and the results reported here. As mentioned before, Table 1 shows the $\mathrm{Zn}$ content and will be discussed later again in this section.

The TAD crystallinity results of the smaller sample will be shown here, based on the $\omega$-scans. The TAD used the (333) reflection as determined by Laue back reflection. Fig. 4 details the orientation of the small sample, which was etched with a $3 \%$ bromine/methanol solution for $3 \mathrm{~min}$ and subsequently re-etched with $1 \%$ bromine/ methanol solution for $3 \mathrm{~min}$. Figs. 5 and 7 are the TAD $\omega$-scans of the front and back of the sample. One can see that the measured sample has a FWHM of 24.2 arcsec in the front part (Fig. 5). The back of the same sample is composed of several grains, which have values of FWHM, varying between 16 to 21 arcsec. The multiple peaks are due to tilt regions within the sample. This is supported by the topographs to be discussed later. The TAD $\omega$-scans results should be compared with the average value of HPVB CZT obtained by Dr. H. Yoon [14] for Sandia National Laboratories in Livermore CA, and shown in Table 4. We can see that the values obtained for HB CZT correspond to medium or somewhat better than medium values of HPVB CZT.

Table 4. Average FWHM values for $\omega$-TAD Scans obtained for CZT detectors

\begin{tabular}{|l|l|l|l|}
\hline HPVB (high quality) & HPVB (medium quality) & HPVB (low quality) & HB \\
\hline$<10$ arcsec & $>40$ arcsec & $\sim 300$ arcsec & 20 arcsec \\
\hline
\end{tabular}

The data in Table 4 should be compared with GaAs whose -TAD rocking curve $\omega$-scan FWHM is only 4 arcsec. In order to better understand the $\omega-$ TAD scans we refer to ref. 14 .

Table 5. Summary descriptions of the three TAD $\omega$-scans

\begin{tabular}{|l|l|l|}
\hline TAD result & FWHM (aresecs) & Characteristic feature \\
\hline (A) High crystal quality & 8 & Single, narrow peak \\
\hline (B) Tiit boundary & 50 & Two (or more) resolvable peaks \\
\hline (C) Mosaic structure & 45 & Single, broadened peak \\
\hline
\end{tabular}

The FWHM revealing the tilt boundary is measured as the angular separation between the half intensity of the left peak to the half intensity of the right peak As a comparison, under the same experimental conditions, a typical silicon crystal exhibits a single narrow peak of FWHM $=3.5$ arcsecs using the (004) reflection. Thus we can conclude that HB has a lower crystalline perfection than best HPVB CZT.

The $\theta / 2 \theta$ scans (Figs. 5,7) are supposed to show the strain in the samples which are caused by the variation of the $Z n$ content. Figs. 5 and 7 are the $\theta / 2 \theta$ scans of the front and back of the sample, respectively. However, when compared to the data of other bulk HPVB CZT it can be seen that this sample has a smaller FWHM, which would mean that there is a lower composition gradient in the region where this sample was analyzed. 
A $\omega$-scan taken of the sample during topography can be seen in Figures 6 and 8. The points labeled A, B, C, and D (Fig. 6) are the places at which topographs were taken (Fig. 9 A-D respectively) using Kodak DEF5 film. Only spot D was imaged using high resolution Kodak SRI film. Notice how different areas of the crystal are imaged at the different points of the rocking curve, indicative of the presence of tilt between the grains of the sample.

HB-CZT (small sample)

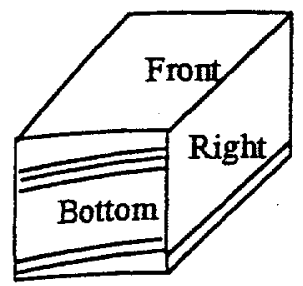

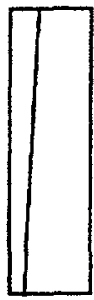

Left

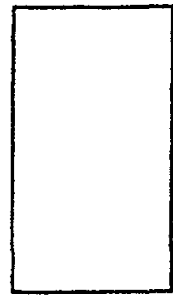

Front

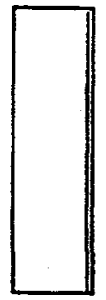

Right

Fig. 4: Schematic detailing the orientation of the sample during measurements.

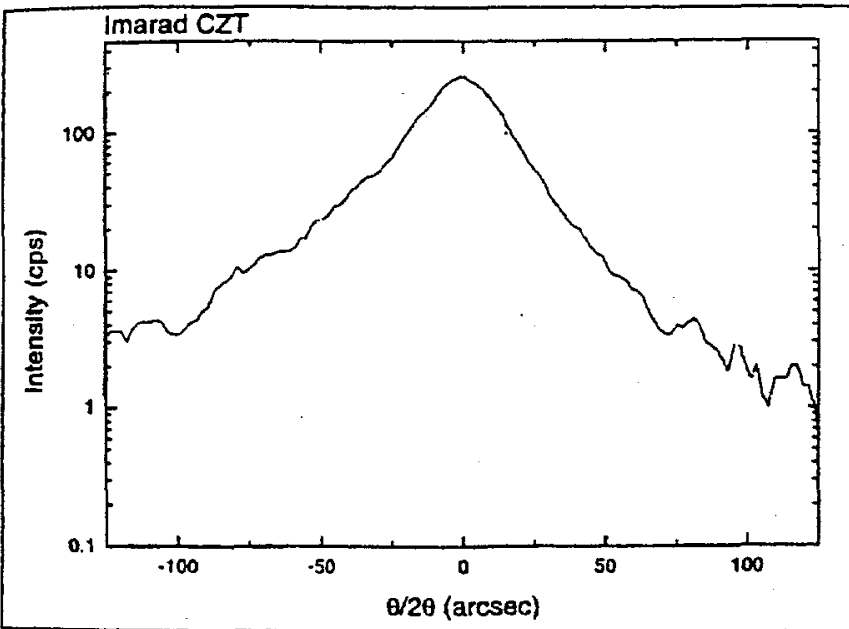

Fig. 5. $\theta / 2 \theta$ scan taken of the $\mathrm{HB}$ CZT sample

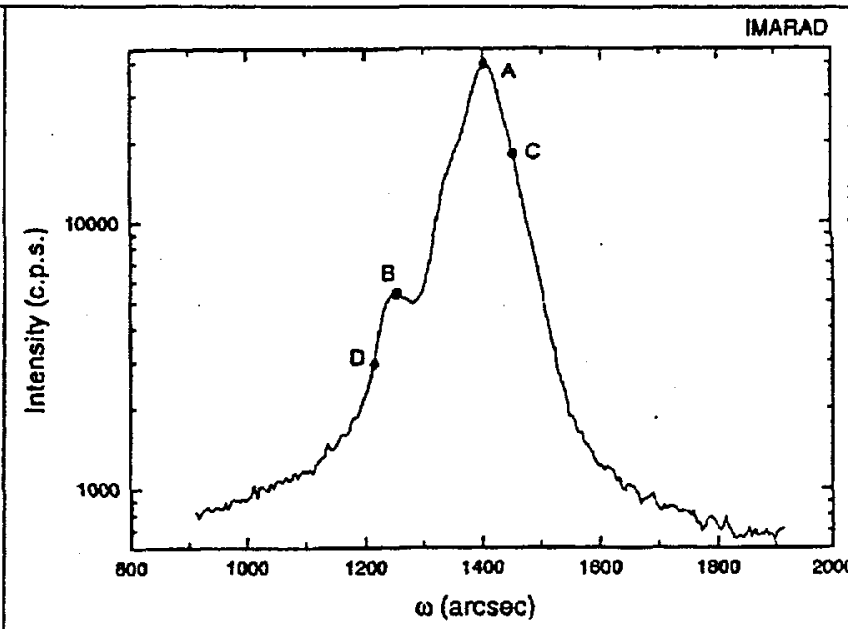

Fig. 6. $\omega$-scan taken of the HB CZT sample

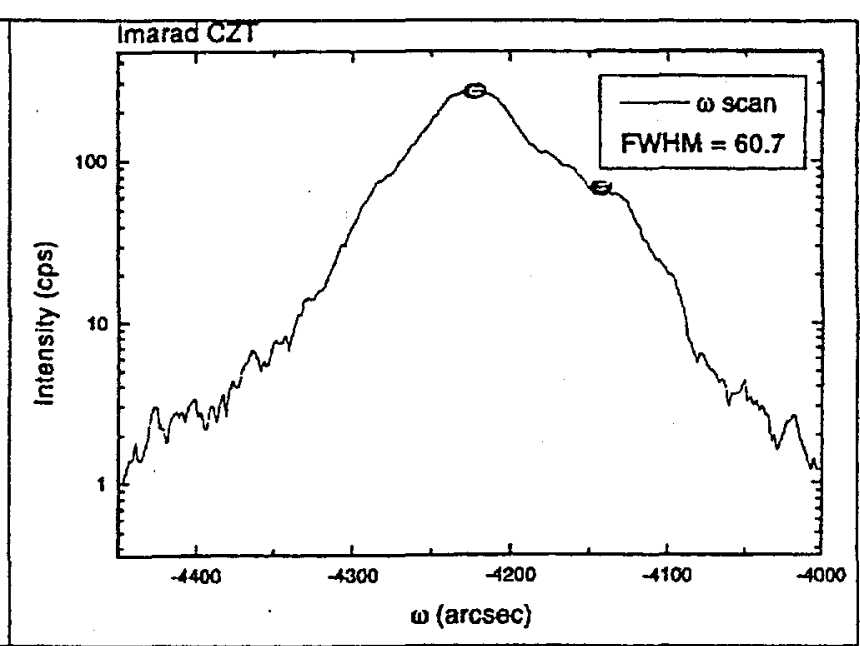

Fig. 8. $\omega$-scan taken of the HB CZT sample 


\subsubsection{X-ray topography}

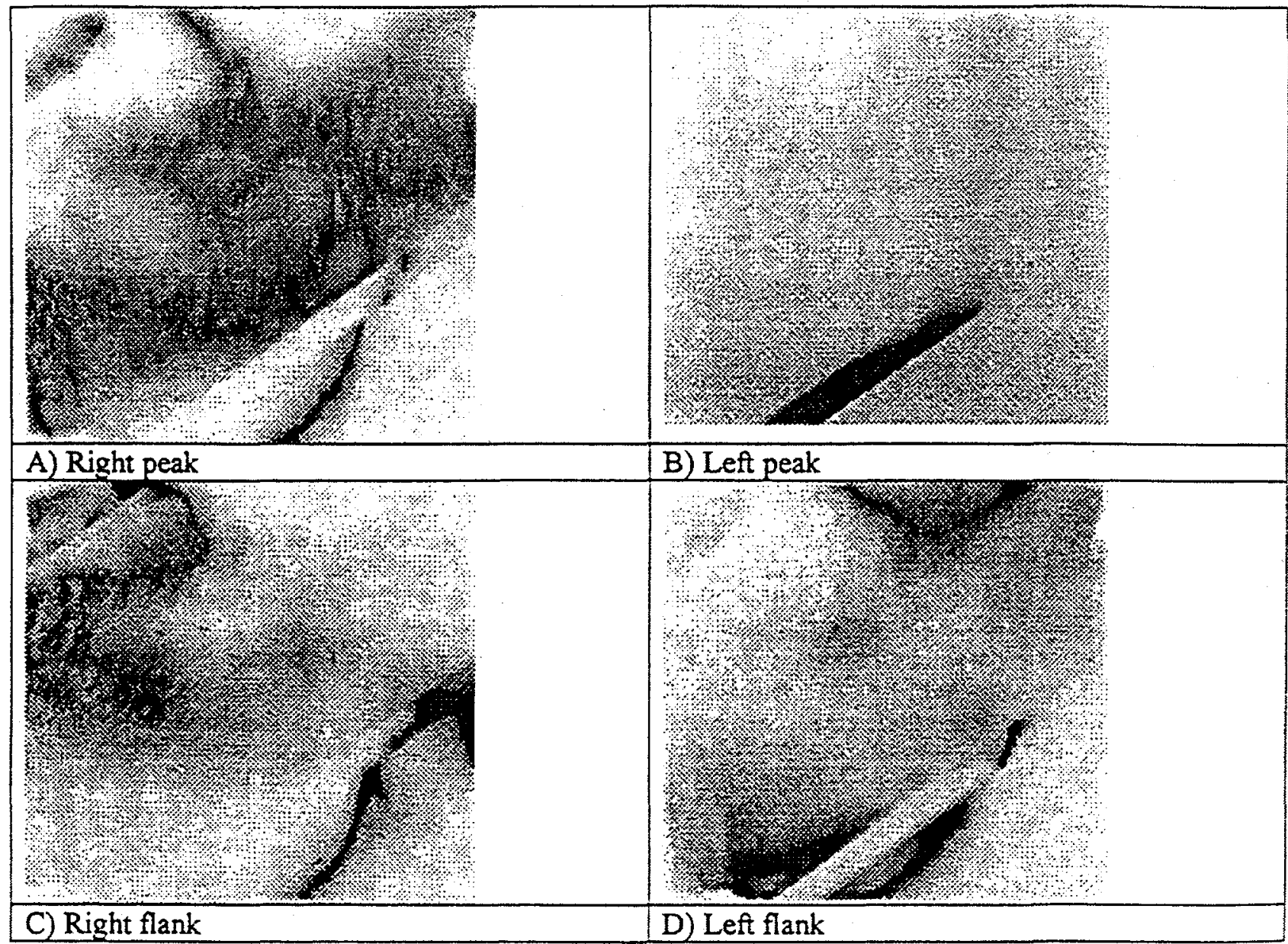

Fig. 9. X-ray topography of Imarad CZT at several points. Black area represents bad crystallinity.

The black regions in Figure 6 are out of the Bragg angle diffraction peak, and therefore show the tilted region. In summary, the crystallinity of HB CZT is worse than for the best HPVB CZT, but the homogeneity of the Zn content seems to be better.

\subsection{TEVS and TSC results}

A new method, Thermoelectric voltage spectroscopy (TEVS), has been developed recently in combination with thermally stimulated currents (TSC) for studying deep levels and compensation [16]. In TEVS, the thermoelectric voltage across a sample is measured as a function of the temperature, during the thermal stimulation of the electron and the hole traps. The TEVS voltage shows steps that reflect (1) the change of the electron and hole quasi-Fermi levels due to detrapping and (2) the trap type, whether electron or hole. A simple product rule holds between the TEVS voltage, TSC current, and TEES current, when identical trap filling and heating are done. The combination of TSC and TEVS is a powerful way for studying compensation and deep levels in semi-insulating wide energy band gap materials.

Two CZT samples, one is HPVB grown eV Products and the other is HB CZT grown by IMARAD has been studied using the TEVS and TSC as shown in Figs. 10-13. The two samples were about the same dimensions, being $10 \times 10 \times 2 \mathrm{~mm}^{3}$ and both had thermally evaporated In contacts. The HPB grown sample from $\mathrm{eV}$ Products shows nearly zero TEVS voltage at low temperature and then the TEVS voltage gradually increases up to $310 \mathrm{~K}$ with hole trap emissions. Three dominant TSC peaks at 33,73 , and $173 \mathrm{~K}$ can be seen and the upward slopes of the TEVS voltage at those temperatures tell us that these are all 
hole traps. Using the formula method and propagating uncertainty of the trap cross sections from $10^{-12}$ to $10^{-18} \mathrm{~cm}^{2}$, these traps are found to have thermal ionization energies of $64 \pm 19,156 \pm 42,423 \pm 100 \mathrm{meV}$. The TEVS voltage decrease near $320 \mathrm{~K}$ and this indicates the presence of a deep electron trap with thermal ionization energy of $820 \pm 180 \mathrm{meV}$. Above $360 \mathrm{~K}$, the material becomes intrinsic, i.e. the electron and the hole concentrations becomes comparable and, due to $\sim 10$ times larger mobility of the electrons over the holes, the material becomes n-type. The TSC spectrum of Imarad sample shows a dominant peak at $86 \mathrm{~K}$, corresponding to a hole trap having thermal ionization energy of $190 \pm 50 \mathrm{meV}$. The TEVS spectrum shows emission from shallow hole traps between 12 to $25 \mathrm{~K}$ followed by emission from shallow electrons between 25 to $50 \mathrm{~K}$ that nearly compensates the hole traps, making the TEVS voltage nearly zero. Using the formula method, the hole and the electron trap thermal ionization energies are $40 \pm 12 \mathrm{meV}$ and $70 \pm 22 \mathrm{meV}$, respectively. Then the TEVS voltage monotonically increases to $320 \mathrm{~K}$, indicating detrapping from a series of hole traps, in a manner similar to the HPB grown material. Near $150 \mathrm{~K}$, there is a shoulder in the TSC spectrum, corresponding to a hole trap with energy $360 \pm 86 \mathrm{meV}$. Between $320 \mathrm{~K}$ and $350 \mathrm{~K}$, there is a deep electron trap at $850 \pm 190 \mathrm{meV}$, again like the HPB material. Above $370 \mathrm{~K}$, the material behaves intrinsic. The heating rates for the two samples are not identical, due to slight differences in their dimensions. In summary, the main difference between the $\mathrm{eV}$ Products sample and the Imarad sample is the existence of large concentration of shallow electron and hole traps in the Imarad material. Both materials have deep electron levels at nearly the same energy and have hole traps at nearly the same energies, within the uncertainties we have given.

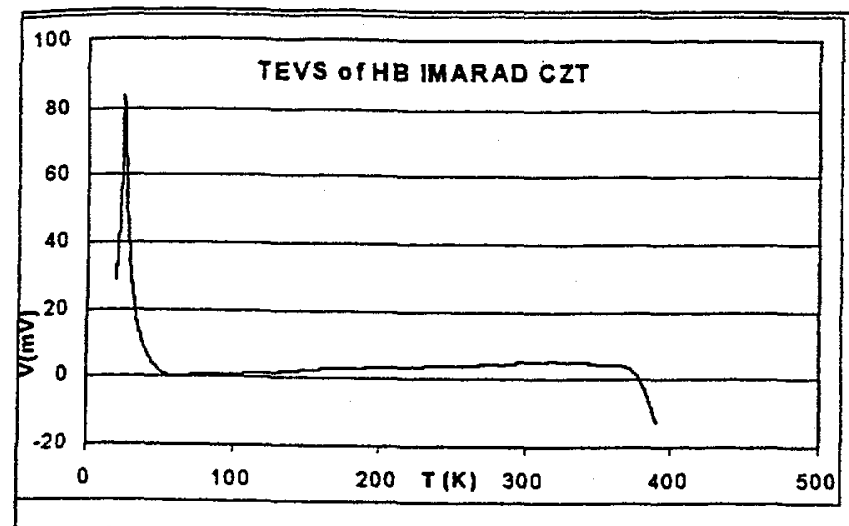

Fig. 10. TEVS of HB CZT

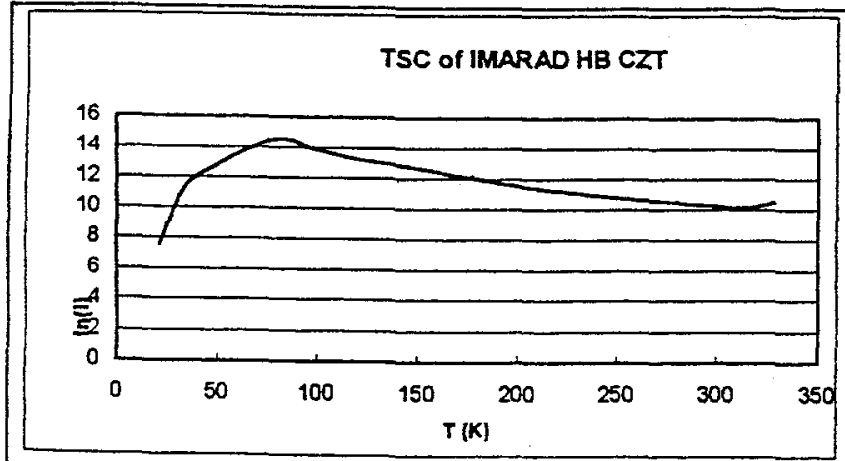

Fig. 12. TSC of HB CZT

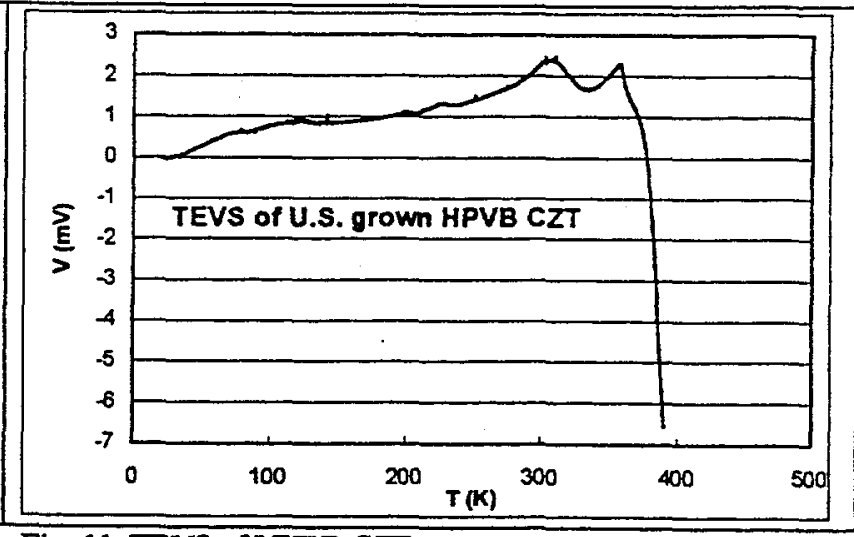

Fig. 11. TEVS of VHPB CZT

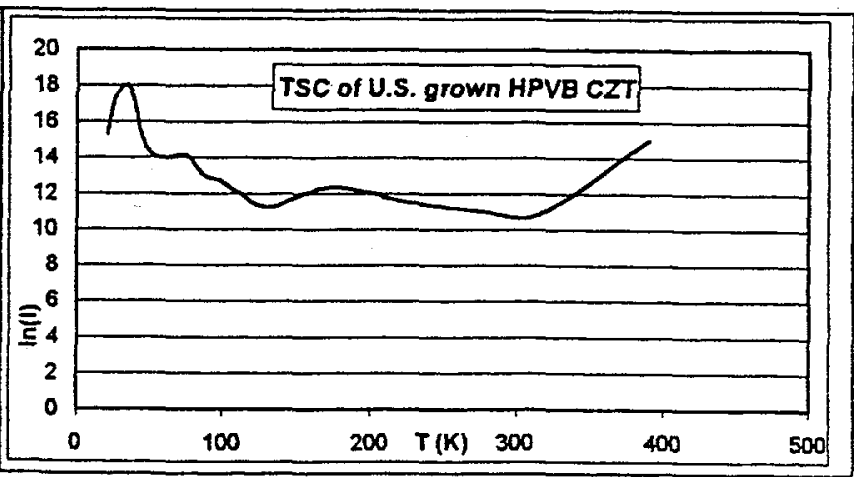

Fig. 13. TSC of VHPB CZT

\section{CONCLUSIONS}

A comparison between spectroscopic grade VHPB and HB crystals is reported. $\omega / 2 \theta$ scans do show a lower crystallinity of the HB crystals but nevertheless they have comparable trapping times and produce good quality nuclear radiation detectors. The HB CZT also has high level of shallow traps which was not found in the U.S. grown HPVB CZT Further evaluation will probably show better the differences between the two type of crystals and their defect structure. 


\section{REFERENCES}

1. J.R. Heffelfinger, D.L. Medlin, H. Yoon, H. Hermon and R.B. James, Proceedings of SPIE Vol. 3115 (1997) 40.

2. J.F Butler, F.P Doty, C. Lingren, B. Apotovsky, Applied Radiation and Isotopes, V. 44 (10-11) (1993) 1359.

3. RB. James, B. Brunett, J. Heffelfinger, J. Van Scyoc, J. Lund, F.P. Doty, C.L. Lingren, R Olsen, E. Cross, H. Hermon, H. Yoon, N. Hilton, M. Schieber, J. Toney, T.E. Schlesinger, M. Goorsky, W. Yao, H. Chen, and A. Burger, J. of Electronic Materials, Vol. 27, No. 6, (1998) 788.

4. J.F. Butler, F.P. Doty, B. Apotovsky, J. Lajzerowicz and L. Verger, Mater. Sci. Engin., B16 (1993) 291.

5. RB. James, T.E. Schlesinger, J. Lund, and M. Schieber, in Semiconductors for Room Temperature Nuclear Detector Applications Semiconductors and Semimetals, Vol. 43, edited by T. E. Schlesinger and R. B. James (Academic Press, New York, 1995) 335.

6. H. Hermon, M. Schieber, R.B. James, N.N. Kolesnikov, Yu.N. Ivanov, V. Komar, M.S. Goorsky, H. Yoon, J. Toney, and T.E. Schlesinger, Vol. 487, edited by R.B. James, T. E. Schlesinger, P. Siffert, W. Dusi, M. Squillante, M. O'Connell and M Cuzin (Materials Research Society, Pittsburgh, PA, 1998) 223.

7. N.N. Kolesnikov, A.A. Kolchin, D.L. Alov, Yu.N. Ivanov, A.A. Chernov, M. Schieber, H. Hermon, R.B. James, M.S. Goorsky, H.Yoon, J. Toney, B. Brunett, T.E. Schlesinger, J. Cryst. Growth 174 (1997) 256.

8. M. Schieber, H. Hermon, RB. James, J. Lund, A. Antolak, D. Morse, N.N. Kolesnikov, Yu.N. Ivanov, M.S. Goorsky, J.M. Van Scyoc, H. Yoon, J. Toney, T.E. Schlesinger and F.P. Doty, IEEE Trans. on Nucl. Sc. 4 (1997) 2566.

9. M. Schieber, H. Hermon, R B. James, J. Lund, A. Antolak, D. Morse, N.N. Kolesnikov, Yu. N. Ivanov, M.S. Goorsky, H. Yoon, J. Toney and T.E. Schlesinger, Proceedings of SPIE, Vol. 3115 (1997) 305.

10. H. Hermon, M. Schieber, R.B. James, J. Lund, A. Antolak, D. H. Morse, N.N.P. Kolesnikov, Yu.N. Ivanov, V. Komar, M.S. Goorsky, H. Yoon, J. Toney and T.E. Schlesinger, in Semiconductors for Room Temperature Radiation Detector applications II, V 487, edited by R.B. James, T. E. Schlesinger, P. Siffert, W. Dusi, M. Squillante, M. O'Connell and M. Cuzin (Materials Research Society, Pittsburgh, PA, 1998) 13.

11. H. Hermon, M. Schieber, R.B. James, A. Antolak, D. H. Morse, B.A. Bnunett, C. Hackett, E. Tarver, V. Komar, M.S. Goorsky, H. Yoon, N.N.P. Kolesnikov, J. Toney and T.E. Schlesinger, ICCG Workshop, Jerusalem, July, 1998, to be published in NIM, Section A.

12. E.Y. Lee, B.A. Brunett, R.W. Olsen, J.M VanScyoc, H. Hermon and R.B. James, Proceedings of SPIE, Vol. 3446 (1998) 40.

13. H. Hermon, M. Schieber and M. Roth, Nucl. Inst. and Meth. A380 (1996) 10.

14. H. Yoon, Ph.D. thesis, UCLA, 1999

15. R. Koehler, High-resolution X-ray topography. Appl. Phys. A 58 (1994) 149.

16. E.Y. Lee, R.B. James, R.W. Olsen, and H. Hermon, J. of Electronic Mater. 28, (1999) 766. 